Volume, 14, número 1, ano, 2018.

\title{
A REPRODUTIVIDADE DE VALORES ÉTICOS POR MEIO DAS PRÁTICAS DOCENTES
}

\author{
Joao Pedro Antunes de Paulo ${ }^{1}$
}

\begin{abstract}
RESUMO O interesse central deste texto é discutir a reprodutividade de valores éticos a partir de outra perspectiva de formação e prática docente. Tomando como fundamentação teórica o Modelo dos Campos Semânticos, apresentamos um outro pressuposto de comunicação: comunicação como um processo de compartilhamento de direções de interlocução, para dar visibilidade a nossa perspectiva de formação de professores. Apontamos então aspectos para se pensar as práticas docentes a partir desta perspectiva e como os valores éticos, entendidos como patrimônio cultural, são reproduzidos (ou não) por meio de determinadas práticas. Apresentamos por fim, as contribuições que as noções de estranhamento e descentramento, tomadas do referencial teórico, podem trazer para a formação inicial de professores.
\end{abstract}

Palavras-chave: Modelo dos Campos Semânticos. Formação de professores. Estranhamento.

\section{THE REPRODUCIBILITY OF ETHICAL VALAUES THROUGH TEACHING PRACTICES}

\begin{abstract}
The central concern of this study was to investigate the reproducibility of ethical values from another perspective of teacher training and practice. Taking as theoretical foundation The Model of Semantic Fields, we present another notion of communication: communication as a process of sharing of interlocution directions, to give visibility to our perspective of teacher training. We then point out aspects to consider teaching practices from this perspective and how ethical values, understood as cultural patrimony, whether or not they are reproduced by certain practices. We present, finally, the contributions that the notions of defamiliarization and decentration, taken from the theoretical referential, can bring to the pre-service teacher training.
\end{abstract}

Key-words: Model of Semantic Fields. Teacher training. Defamiliarization.

\section{INTRODUÇÃO}

Este trabalho tem como referencial teórico o Modelo dos Campos Semânticos, modelo teórico que tem contribuído no desenvolvimento da área de Educação Matemática, com trabalhos que versam sobre a formação docente, os conhecimentos matemáticos do

\footnotetext{
${ }^{1}$ Doutorando em Educação Matemática pela Universidade Estadual Paulista campus de Rio Claro, com mestrado também em Educação Matemática pela mesma instituição. Tem experiência profissional na docência em Educação Básica e Ensino Superior. Atuou como professor substituto na Universidade Federal de Goiás, Regional Jataí. No campo investigativo, seu interesse se concentra na formação inicial de professores. Faz parte dos grupos de pesquisa FEM /UNESP/ RC e NuFOPE/ UFG/ Jataí.
} 


\section{REVISTAELETRONNICA

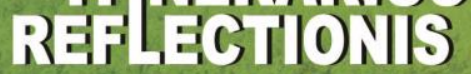

Volume 14, número 1, ano 2018.

professor e também a epistemologia do conhecimento. Trazemos aqui a perspectiva de formação de professores com a qual temos trabalhado, para isso apresentamos alguns pressupostos do modelo teórico que acreditamos são necessários para a discussão desta perspectiva.

Apresentamos também de modo breve a metodologia que guiou esta pesquisa, a produção das reflexões que apresentamos neste texto. Elaboramos então, um exercício de pensar como os valores éticos são reproduzidos a partir desta nossa perspectiva de formação de professores e, por fim, apontamos para discussões que podem contribuir para esta área de pesquisa que é a formação de professores.

\section{OBJETIVOS}

O objetivo central deste texto é apresentar e discutir uma outra perspectiva para a formação de professores, que está centrada em uma leitura das interações que ocorrem dentro da sala de aula. Esta proposta está situada em um referencial teórico que vem contribuindo com pesquisas na área da Educação Matemática e que nos últimos anos se volta a pensar a formação de professores de modo mais abrangente.

Articulado ao objetivo geral deste estudo, desenvolvemos, em específico, um exercício de se pensar como os valores éticos, e com isso uma constituição do ser professor que é socialmente aceito, são reproduzidos, ou não, por meio das práticas docentes.

\section{METODOLOGIA DE PESQUISA}

Uma metodologia não é meramente um conjunto de métodos procedimental, como afirma Garnica (2012), pois esta está ligada às vivencias do pesquisador, à sua concepção de mundo e a seus fundamentos teórico-filosóficos. A metodologia é um conjunto de mecanismos que se relacionam a todo este universo do pesquisador fornecendo-lhe meio eficaz de compreender determinada situação. 


\section{REVISTA ELETROONICA \\ thlyialinus REFilicillonis

\section{Volume 14, número 1, ano 2018.}

Neste artigo nos aproximamos de uma investigação descritiva e a análise se deu a partir do entendimento do pesquisador sobre o material produzido. Estas características, de acordo com Bogdan e Biklen (1994), nos aproximam de uma pesquisa qualitativa. Flick (2009) ressalta também com relação às pesquisas qualitativas que estas buscam entender como as pessoas constroem o mundo a sua volta e como agem dentro dele descrevendo de uma maneira que ofereçam uma visão rica desta "realidade".

Esta é uma pesquisa bibliográfica, os dados foram constituídos a partir da leitura da dissertação de mestrado (PAULO, 2016). Articulando à esta fonte, buscamos autores que versam sobre o referencial teórico adotado (OLIVEIRA, 2011; VIOLA DOS SANTOS, 2012) e também sobre o tema Ética (COMPARATO, 2006; HEGEL, 1997), que se configura como noção específica nos objetivos deste estudo. A análise dos dados deu-se a partir do referencial teórico adotado: Modelos dos Campos Semânticos (LINS, 2003, 2004, 2012) e consistiu na produção de reflexões em torno da temática "dialética do trabalho docente: entre ética e ensino". Intenciona-se, com estas reflexões, contribuir para as discussões na área de formação de professores e ainda propor outras direções para o trabalho que vem sendo desenvolvido pelo autor.

\section{REFERENCIAL TEÓRICO: Sobre o Modelo dos Campos Semânticos}

Para falar de como pensamos a docência, aqui entendida como o conjunto de práticas do professor, precisamos por em evidência o que cremos ser central nesta perspectiva: a noção de comunicação. Assim como Lins (1997) acreditamos que a docência está organizada da forma atual devido ao pressuposto da comunicação efetiva, ou seja, o professor fala e o aluno entende; existe entre eles a transmissão de uma mensagem.

No entanto, para nós, a comunicação se dá de uma outra forma, que apesar das diferenças, também possui como noção central o significado. O que torna nossa perspectiva diferente é que nela não há comunicação efetiva, os significados são produzidos por cada um dos participantes do processo comunicativo. Nesta perspectiva existem três elementos necessários para a comunicação: Autor, Texto e Leitor. 


\section{REVISTA ELETROONICA \\ tyltipainus ReFlizontlonis

\section{Volume 14, número 1, ano 2018.}

O Autor ${ }^{2}$ é quem produz uma enunciação, esta não se restringe a fala, pode ser escrita, gestos, a organização das coisas... Sempre que produz essa enunciação o Autor fala (gesticula, desenha...) em direção a um leitor, esta é uma direção cognitiva, um leitor não necessariamente coincide com um sujeito biológico, mas é criado, instituído, pelo Autor no momento da enunciação. Comumente substituímos a expressão "leitor" por direção de interlocução, na tentativa de evitar a associação com um sujeito biológico.

Esta direção de interlocução para a qual o Autor fala é criada por ele e instituída como legitima, ou seja, tudo o que ele diz pode ser dito e será aceito. "Quem fala não espera que [a direção de interlocução] responda, mas a mera existência [da direção de interlocução] (a impossibilidade da solidão) instaura a dialogia” (LINS, 2012, p. 19, comentário nosso).

A enunciação produzida pelo Autor é o que chamamos de Texto, mas, como ressaltamos, a enunciação não se restringe a fala ou escrita, desta forma Texto, não se restringe ao que é escrito, pode ser também os sons que produzimos, as imagens que pintamos, a ordem das coisas como as organizamos, os gestos, as expressões faciais, o modo de se vestir... Convém ressaltar ainda que o Texto existe somente no momento da enunciação, quando esta cessa o Texto deixa de existir.

Do outro lado, o Leitor se encontra com algo que acredita foi dito por alguém, chamamos este algo de resíduo de enunciação, isto é, aquilo que resta de um processo comunicativo. O resíduo pode ser sons, rabiscos, organização das coisas, gestos, imagens... mas, ele é de uma ordem diferente da enunciação. A presença deste resíduo coloca a demanda de produção de significado para aquele algo, demanda esta que é atendida pelo Leitor (Lins, 2012).

Para produzir significado para aquele resíduo o Leitor constitui uma direção de interlocução para a qual produzirá uma enunciação. Esta enunciação é feita a partir dos resíduos com os quais ele se deparou. O Leitor produz significados que considera legítimos, em uma direção de interlocução em que o que ele diz pode ser dito e é aceito.

Assim como o Autor, o Leitor é quem produz os seus significados a partir daquele resíduo de enunciação que ele se deparou, assim sendo o Leitor também é autor. Ele não é

2 Autor e Leitor grafados com iniciais maiúsculas referem-se a pessoas participando de um processo comunicativo, enquanto autor e leitor grafados com iniciais minúsculas referem-se a direções de interlocução constituídas pelos sujeitos da enunciação. 


\section{REVISTA ELETROONICA \\ GRADUAÇ, ÁO/PÓS-GRADUAÇÃO EM EDUCAÇÃO \\ UFG/REJ}

* ISSN . 1807-9342

\section{Volume 14, número 1, ano 2018.}

interprete, decodificador, coautor e qualquer outra coisa que não autor de seus significados.

Neste sentido acreditamos na morte do leitor, ou seja, somos todos autores dos significados que produzimos (LINS, 2012). Um texto, um resíduo de enunciação, não transmite nenhum significado, apenas dispara a produção deste.

Mas como então temos a sensação de comunicação efetiva?

Nossas direções de interlocução "marcam, em última instância, [...] o horizonte cultural, os limites do possível, já que eles são as marcas da legitimidade, do que pode ser dito.” (LINS, 2012, p. 19, grifo do original). Sendo assim, todo o processo é cerceado pela cultura e, dentro de cada cultura existem as possibilidades consideradas legítimas, aceitáveis, sendo estas utilizadas pelos participantes desta cultura. As direções de interlocução "são legitimidades. O que internalizamos, nos processos de humanização e do que se costuma chamar de desenvolvimento intelectual, são [direções de interlocução], são legitimidades." (LINS, 2012, p. 20, comentário nosso).

A noção de comunicação é substituída então pela noção de espaço comunicativo, um processo no qual direções de interlocução são compartilhadas. "Numa inversão conceitual, 'comunicação' não corresponde mais a algo do tipo 'duas pessoas falando uma para a outra', e sim a 'dois sujeitos cognitivos falando [em uma mesma direção de interlocução]" (LINS, 2012, p. 24, comentário nosso).

A sensação de comunicação efetiva reside na aparência da existência de um espaço comunicativo: falamos em uma mesma direção de interlocução por isso nos entendemos. Dizemos aparência porque não temos garantia da existência do espaço comunicativo, por exemplo:

Professor: Muito bem, temos a equação $3 x+10=100$. Podemos concluir, então, que $3 \mathrm{x}=90$, certo?

Alunos: Certo.

Professor: E disso podemos concluir que $\mathrm{x}=30$, certo?

Alunos: Certo.

Na lição de casa, entre outras, a equação $3 x+100=10$.

Os alunos já sabiam operar com inteiros negativos. No dia seguinte a maioria das equações resolvidas sem problemas, mas na hora da $3 \mathrm{x}+100=10 \ldots$

Alunos: Professor, esta não dá... (LINS, 2012, p. 25). 


\section{REVISTA ELETROONICA \\ GRADUAÇÃO/PÓS-GRADUAÇÃO EM EDUCAÇÃO \\ UFG/REJ}

ISSN . 1807-9342

\section{Volume 14, número 1, ano 2018.}

Aparentemente, em sala de aula, professor e alunos estavam em um espaço comunicativo, compartilhavam direções de interlocução, pois estavam concordando com os processos de resolução da equação. Entretanto, a aparência do espaço do comunicativo não se confirma quando o professor propõe uma equação do tipo $3 x+100=10$ como lição de casa. Os alunos não sabem como resolver esta equação, ou seja, os alunos pensavam com alguns objetos que eram diferentes dos objetos com os quais o professor pensava e o espaço comunicativo entre eles durante a aula era apenas uma aparência. Por isso é preciso ler nossos alunos.

O professor pensava com as regras, com a linguagem matemática, pensava algebricamente, enquanto seus alunos, dentre outra possibilidades, pensavam em balanças de dois pratos, ou seja, pensavam em "manter o equilíbrio" da equação. Se de um lado eu tenho três objetos iguais mais um peso de 10 gramas e do outro lado eu tenho um peso de 100 gramas e a balança está equilibrada, quer dizer que tirando dez gramas de cada lado e dividindo as 90 gramas que restam entre os três objetos, cada um só pode pesar 30 gramas. Esta mesma lógica não cabe na equação $3 x+100=10$ porque é impossível que uma balança que tenha três objetos iguais mais 100 gramas de um lado e do outro apenas 10 gramas esteja equilibrada.

A lógica do equilíbrio da balança e a linguagem algébrica geraram a aparência de mesma direção de interlocução em determinados casos, entretanto professor e alunos falavam de coisas diferentes, por isso dizemos que é apenas aparência. Se o professor não lê os seus alunos, se ele não busca saber com quais objetos eles estão pensando, esta aparência pode perdurar e ambos continuarão falando de coisas diferentes como se estivessem "se entendendo".

Na sala de aula o processo comunicativo se dá a todo momento, e da forma como ela está organizada pressupõe-se a existência da comunicação efetiva, professor fala e alunos entendem. No entanto, se adotarmos a perspectiva de espaço comunicativo como a base da organização da sala de aula uma nova perspectiva de formação (seja em nível superior ou básico) estará em evidência.

\subsection{Uma concepção de formação a partir desta perspectiva}




\section{REVISTA ELETROONICA \\ HyHalinus REFilicillonis

\section{Volume 14, número 1, ano 2018.}

Há algum tempo temos nos dedicado ao estudo da formação de professores a partir deste referencial teórico. Nossos esforços se unem ao de outros integrantes do grupo de pesquisa na tentativa de organizar esta perspectiva de modo sólido e abrangente. Importa-nos principalmente os aspectos gerais da formação docente que de modo algum pode ser pensada restrita aos espaços universitários de formação inicial.

Tomando então como pressuposto o processo de constituição de direções de interlocução, conforme descrito anteriormente, pensamos a formação docente baseada no processo de humanização. Tornamo-nos professores à medida que somos internalizados por práticas que são reconhecidas e legitimadas como sendo práticas docentes.

Neste ponto surge questões relevantes que de modo algum devem ser banalizadas ou ignoradas. Como se dá o processo de internalização? Por que são estas as práticas reconhecidas? Quem as reconhece? Quem as legitima? Quem as instituiu? E, ao pensar nestas questões, somos levados a interrogações ainda mais abrangentes: O que é cultura? Como a cultura é definida? Como é reproduzida?

Não esperamos apresentar respostas definitivas para estas interrogações, pelo contrário, acreditamos na potência da pergunta, no que ela nos provoca, mais do que nas respostas que definem, que instituem. Deste modo queremos registrar aqui um movimento disparado por estas perguntas, tendo por objetivo contribuir com as discussões originadas em torno do tema "dialética do trabalho docente: diálogos entre ética, ensino e práxis".

Retomando nosso ponto de partida a fim de caminhar na direção das interrogações postas anteriormente, argumentaremos a respeito da formação docente como um processo de constituição de direções de interlocução. Neste sentido, o pressuposto da comunicação, como exposto, a constituição de direções de interlocução se dá a todo momento, a cada processo de produção de significado no qual o sujeito se coloca, desde a infância até a sua morte.

Temos também que este é um processo cerceado pela cultura, ela delimita os horizontes do possível, do que pode ser dito. Na infância estes horizontes, estas barreiras são mais esparsas, difusas, neste sentido é comum encontrar crianças dizendo "o que não pode ser dito": 


\section{REVISTA ELETROONICA \\ thlyialinus ReFlizontlonis

\section{Volume 14, número 1, ano 2018.}

Mãe: Meu filho, somente os pássaros podem voar

João: Então eu quero ser um pássaro

(DANTAS, FERREIRA, PAULO, 2016, p. 216-217).

Como analisados pelos autores, a criança ao produzir este tipo de enunciação está lidando com uma lógica própria da infância, que é diferente da lógica do mundo dos adultos (ANGELO, 2012).

Quando falamos em lógica, queremos dizer que as direções de interlocução constituídas por esta criança não pertencem ao horizonte cultural dos adultos, ela extrapola, subverte a ordem e produz enunciações que não são consideradas legítimas pelos adultos, entretanto, em seu horizonte cultural, ou seja, na lógica da criança, essas afirmações são legitimas.

Mas como é definido o que é legítimo e o que não pode ser dito dentro de uma cultura?

Como afirma Lins (2012, p. 22) "A luta pelo controle de quais são os modos de produção de significado legítimos é o próprio processo de determinação de horizontes culturais (as fronteiras)". O autor afirma ainda que esta luta pelo controle é uma luta por poder dentro de culturas (sociedades) e "[...] como a produção de significado é sempre local, sempre e inevitavelmente este controle vai ser frágil e temporário, cheio de fissuras e rachaduras." (idem).

A cultura, desta nossa perspectiva, é então, algo frágil em constante mudança que atende sempre ao resultado de uma luta por poder. Enquanto sujeitos cognitivos neste jogo por controle, temos a necessidade de pertencimento, assim como biologicamente temos a necessidade de alimentação e reprodução. $\mathrm{O}$ instinto de sobrevivência do nosso cognitivo se manifesta no desejo de pertencer à cultura, ser internalizado, pertencido a ela. Atendemos a este desejo produzindo significado e, o fazemos em uma direção de interlocução que é considerada legítima por aquela cultura, pois é a ela que queremos pertencer, é por ela que queremos ser aceitos. A produção de significado é então uma estratégia de sobrevivência (LINS, 2012).

Desde modo, quando na infância sentimos o desejo de sobrevivência começamos a produzir significado em outras direções na esperança de sermos aceitos naquele outro 


\section{Volume 14, número 1, ano 2018.}

mundo, o mundo dos adultos. Podemos afirmar como uma manifestação desse desejo a preocupação com a resposta "certa", ou seja, o que eu estou dizendo é algo que você diria?

Esta luta pela sobrevivência, a busca por direções de interlocução legítimas em determinado contexto social, nos coloca em um processo de pertencimento, vou sendo internalizado por legitimidades daquela cultura e começo a fazer parte dela. Somos membros legítimos quando conseguimos antecipar a legitimidade da nossa fala. Essa antecipação se torna possível na medida em que constituo um repertório de modos de produção de significado, por meio das interações e sucessivas tentativas de falar para e a partir daquela cultura.

Vou deixando de utilizar determinadas direções de interlocução, legitimidades, à medida que vou pertencendo à cultura. Por isso quando um adulto diz que quer voar, é comum (legítimo) pensar que ele se refere a comprar uma passagem aérea para algum lugar, e não levantar voo como um pássaro e sair "caminhando" pelo céu.

Mas este processo não acontece apenas na transformação da infância em maioridade (no sentido legal). É um processo que acontece em culturas (modos de agir, de ser) menores, como, por exemplo, a cultura do médico, do advogado, do gastrônomo, do professor. Cada uma destas culturas é regida por um contrato de modo de agir, para pertencer a alguma delas e ser aceito como membro legítimo, o sujeito deve falar de determinada forma. Este processo de determinação de formas de falar do médico, do advogado, do gastrônomo, do professor é o processo de constituição de direções de interlocução consideradas legítimas por essas culturas.

No caso do professor este é um processo que difere das demais culturas, porque apesar de ir ao médico por várias vezes durante a sua vida é apenas na formação inicial, graduação, que o aluno terá um convívio mais próximo com a profissão, enquanto que o aluno que quer se tornar professor possui este convívio com a profissão desde seus primeiros anos escolares.

Para além da constituição formal da profissão, esta também é cerceada pela cultura em sua maior amplitude; os interlocutores que são constituídos fora dos contextos formais da profissão não devem ser desconsiderados no processo de formação inicial. No caso dos professores, não podemos restringir a formação inicial aos anos de licenciatura, esta 


\section{REVISTAELETRONNICA \\ GRADUAÇ, ÁO/PÓS-GRADUAÇÃO EM EDUCAÇÃO \\ UFG/REJ}

ISSN : $1807-9342$

\section{Volume 14, número 1, ano 2018.}

constituição dos modos de ser professor é um processo que pertence também a cultura mais ampla.

O que pode então a licenciatura neste cenário tão amplo?

Partimos da concepção de que

[...] não é possível pensar que a formação acontece em um único espaço, ou apenas quando se fala em determinadas direções - ao falar com os professores formadores cabe aos cursos de licenciatura se constituírem como um espaço de discussão destas formações. (PAULO, 2016b, s.p.).

Nesta perspectiva, então, a formação inicial é um espaço de explicitação e discussão de direções de interlocução constituídas em diferentes contextos. Alunos e professores discutiriam a legitimidade de diferentes direções de interlocução quando colocadas em contraste com os contextos culturais a partir dos quais eles falam, ou para os quais eles querem falar. Neste novo lugar ganharia espaço o "educar o olhar do professor para ver a diferença e lidar com ela" (LINS, 2003, p. 14).

O educar o olhar passaria pelas perspectivas de estranhamento e descentramento. A noção de estranhamento apresentada por Lins (2004, p. 116) refere-se a situações de interação nas quais existem "aquele para quem uma coisa é natural - ainda que estranha - e de outro aquele para quem aquilo não pode ser dito".

O estranhamento surge então quando coisas que estão além do horizonte cultural de um dos envolvidos na interação são colocadas em jogo. Para este envolvido esta coisa não existe, não pode ser dita, um exemplo de estranhamento é um relógio que não mede a hora, mas os meses do ano (CARROLL, 2009). Ou ainda, falando de Matemática, "não é possível contar os [números] reais com os [números] naturais, fazer uma lista eles, embora seja possível contar os [números] racionais" (informação verbal) ${ }^{3}$; infinitos de tamanho diferente.

A Matemática, por sua característica internalista, oferece-nos grandes oportunidades de estranhamento:

Um matemático pode definir "qualquer coisa" e desenvolver uma teoria para "qualquer coisa". Essa "qualquer coisa" não precisa ter relação alguma com algo que exista no mundo físico - muitas vezes, mesmo havendo essa relação, prefere-se

3 Palestra ministrada por Romulo Campos Lins na abertura da $2^{\mathrm{a}}$ Semana de Matemática, no Instituto Federal de Educação, Ciência e Tecnologia de Goiás, em Goiânia, em outubro de 2011. 


\section{REVISTA ELETROONICA \\ thlyialinus ReFlizontlonis

\section{Volume 14, número 1, ano 2018.}

expurgá-la, depurá-la da teoria. O que importa é que o que ali for dito esteja de acordo, em conformidade, com os modos legítimos de produção de significados da matemática do matemático (OLIVEIRA, 2011, s. p.).

Lins (2004) e Oliveira (2011) discutem a noção de estranhamento fazendo um paralelo com a ideia de monstros apresentada por Tomaz Tadeu da Silva em um artigo no livro Pedagogia dos Monstros publicado em dois mil. Segundo os autores monstros não são deste mundo, por isso eles, os monstros, seguem regras diferentes e como consequência nos paralisamos diante deles, porque não sabemos o que fazer.

Entretanto, os monstros são da nossa cultura, não conseguimos evitar vê-los, mas também não conseguimos enfrentá-los, então, deixamos que eles fujam, se tornem sombras. "Ao se tornarem sombras, os monstros exercem seu papel nefasto de viver na espreita e de deixar suas potenciais vítimas amedrontadas tão somente com a possibilidade do encontro" (OLIVEIRA, 2011, s.p.). Mas é justamente o fato de o monstro ser da nossa cultura que instaura a relatividade do monstro, ele pode ser monstruoso para nós, mas de estimação para outro. O que é monstruoso hoje pode vir a tornar-se de estimação em seguida (idem).

Para nós a metáfora do monstro diz bem sobre as situações de estranhamento, na medida em que personifica na figura do monstro o desconhecido, o diferente. $\mathrm{O}$ estranhamento é então a percepção do diferente, algo que não pertence ao nosso horizonte cultural, algo que foge a todas as regras estabelecidas, a todas as legitimidades internalizadas. Nesta situação temos que tomar uma decisão e, dentre as possibilidades que temos, duas são as mais cogitadas: deixar de lado e não me importar, o monstro se tornará uma sombra; ou tentar o descentramento, ou seja, “ [...] sair de você como centro e tentar ir para o lugar onde o outro está no centro. Nisso aparece a questão da diferença, ou seja, o que eu vou fazer com isso?[...]" (VIOLA DOS SANTOS, 2012, p. 195).

Não podemos esquecer que quem cria o monstro somos nós, como destaca Lins (2004, p. 117, comentário nosso) "Sou eu quem coloco o monstro monstruoso do outro lado, por que sou eu que produzo - para aquilo - significados segundo um modo de produção de significados no qual o que o [outro] diz não pode ser dito, e por isso aquilo é monstruoso". Daí a importância do descentramento, do interesse pelo outro; não é legítimo segundo meu modo de produção de significado, mas quais as legitimidades do outro? Do que ele está falando? Em algum lugar aquilo deve ser legitimo, que lugar é este? 


\section{REVISTA ELETROONICA \\ thlyialinus REA Fiscilloils

\section{Volume 14, número 1, ano 2018.}

Desta perspectiva não destruímos o monstro, a diferença, mas começamos a lidar com os rastros deixados por ele, na tentativa de constituir uma direção de interlocução para falar com o outro, instituir um espaço comunicativo com ele. $\mathrm{O}$ descentramento não intenciona colonizar o outro, ou tornar a sua diferença normal para nós, a intenção é lidar com a diferença. Ela continua a existir, apenas não fugiremos mais dela.

Enquanto instrumentos nos espaços de formação inicial do professor, o estranhamento e, esperançosamente, o descentramento (porque este depende da escolha de cada aluno em lidar com o diferente), exercem a função de possibilitar uma ampliação do repertório de modos de produção de significados; modos de falar sobre a Matemática, sobre ser professor.

Assim, a formação inicial possibilitaria ao professor se ver em um processo; a formação não se restringe à licenciatura. Desta forma, quando estiver no exercício da sua profissão, o professor que experienciou esta perspectiva formativa poderá perceber que perguntas para as quais não tem respostas, ou situação com as quais não sabe como agir de imediato, não são resultados de uma formação deficitária, mas fazem parte do seu processo de formação (LINS, 2003).

Toda a discussão anterior não se restringe ao que pode ser dito e o que deve permanecer no silêncio. A mesma discussão é válida para o que se pode vestir e o que não se deve, o que pode ser feito e o que não se pode fazer, como se pode andar, comer, rezar, louvar... Todos os modos de agir, de ser, são delimitados, legitimados, de forma semelhante. Todos esses modos são produtos das lutas que delimitam as culturas.

\section{DISCUSSÃO DOS RESULTADOS: a cultura e a ética como produções humanas}

Como mencionamos a alguns parágrafos atrás, a cultura para nós é algo em constante mudança que atende sempre ao resultado de lutas por poder. Estas lutas são travadas pelo controle de quais são os modos legítimos de produzir significado. E como resultado desta batalha temos o horizonte cultual, o limite do que podemos dizer e fazer.

Os modos de produção de significados resultados daquelas lutas pelo poder são considerados legítimos, os modos pelos quais a sociedade deve agir. Estes modos de agir são os valores que cada sociedade possui; liberdade religiosa, de expressão, política... 


\section{REVISTA ELETROONICA \\ GRADUAÇ, ÁO/PÓS-GRADUAÇÃO EM EDUCAÇÃO \\ UFG/REJ}

ISSN . 1807-9342

\section{Volume 14, número 1, ano 2018.}

Estes conjuntos de valores de todos os tipos é o que constitui as culturas (LINS, 2010). Esses valores, como dissemos, são os modos considerados legítimos e alguns deles não são tão explícitos como os citados anteriormente. As vestimentas, por exemplo, constituem um valor em cada sociedade que não é tão explícito assim; não andamos de cueca nas ruas, mas andamos de sunga na praia. A nudez pública é algo extremamente vexatório, a não ser em praias de nudismo. Os valores, tanto os mais quanto os menos explícitos, são utilizados para exercitar a disputa pelo poder dentro das culturas (idem).

A cultura também cria mecanismos destinados a negar a legitimidade de determinados modos de produção de significado. Banir para fora aquilo que não lhe convém. Entre estes mecanismos estão, por exemplo, o silêncio, a risada, a reprovação escolar, a internação psiquiátrica... Todos esses modos dizem que a direção de interlocução para a qual o Autor - nos termos do processo comunicativo apresentado no início deste artigo - está produzindo significado não é aceita naquele espaço. Tratar alguém como comediante, é não dar a ele o direito de "falar a sério" sobre determinado assunto; tudo pode ser dito por que não influenciará a nossa "realidade".

Estes modos de agir, modos de produção de significados legítimos, estão imbuídos de valores. Os que são considerados legítimos passam a ser o modo "natural" das coisas, como as coisas devem acontecer. É este conjunto e modos de produção de significados legítimos que, da nossa perspectiva, constitui o que chamamos de Ética.

Duas acepções se fazem presente no que tange os estudos da Ética, uma que trata a ética como essência do homem, algo ideal, e outra que trata esta como algo disciplinador da conduta do homem.

A primeira fala a língua do ideal para o qual o homem se dirige por sua natureza e, por conseguinte, da "natureza", "essência" ou "substância" do homem. Já a segunda fala dos "motivos" ou "causas" da conduta humana, ou das "forças" que a determinam, pretendendo ater-se ao conhecimento dos fatos. (ABBAGNANO, 2007, p. 380).

Destas duas acepções destacamos a perspectiva de Durkheim, que se aproxima da primeira acepção. Para o autor as crenças comuns aos membros de determinada sociedade formam uma consciência coletiva, por meio de um processo de sedimentação das consciências individuais depuradas das práticas sociais de cada indivíduo, e tal consciência coletiva tem 


\section{REVISTA ELETROONICA \\ GRADUAÇÃO/PÓS-GRADUAÇÃO EM EDUCAÇÃO \\ UFG/REJ}

ISSN : 1807-9342

\section{Volume 14, número 1, ano 2018.}

vida própria (COMPARATO, 2006). Ética dessa nossa perspectiva, como modos de agir (modos de produção de significado) legítimos, afasta-nos da concepção de Durkheim. Os modos de produzir significados só existem nas relações, nas lutas, como salientado, não sendo externos a isso.

Destacamos também a acepção de Hegel, que julgamos próxima a segunda posta por Abbagnano (2007). Para Hegel, a vida ética se realiza dentro das instituições históricas e sociais, segundo o autor "[...] o estado é a realidade em ato da idéia moral objetiva [...]" (HEGEL, 1997, p. 216), nesta concepção se opondo às ideias de Kant de que a moral do indivíduo está no centro.

Assim como Hegel, cremos que o que dá a existência ao estado (sociedade) são os modos de agir dos envolvidos nesta relação. As instituições sociais existem porque determinadas pessoas agem de determinadas formas;

\footnotetext{
uma instituição é um fato, o fato de que umas tantas pessoas se comportam de uma certa maneira (consideram legítimos certos modos de produção de significado e operam segundo eles). Se os soldados não se comportassem de certas maneiras não haveria guerra e nem mesmo exército, etc (LINS, 2012, p. 22).
}

Estes comportamentos não são estáticos, eles compõe as lutas pelo poder dentro das culturas, e ao mesmo tempo que as define, também as extrapola. É nestes processos de definição e extrapolação da cultura que o processo de humanização ocorre, o processo de constituição de direções de interlocução é definido também neste cenário fluído. Ou seja, ao constituir interlocutores estamos reproduzindo ou subvertendo a cultura. Trabalhando a favor da legitimação de certas práticas e deslegitimação de outras.

\section{CONSIDERAÇÕES FINAIS}

Apresentamos aqui a concepção teórica a partir da qual temos pensado a formação de professores. Para nós esta se dá no processo de constituição de direções de interlocução, processo este que a partir do nosso referencial teórico substitui o tradicional paradigma da comunicação como transmissão de uma mensagem. Na expectativa de contribuir com as discussões em trono da formação inicial do professor, fizemos um esforço de pensar como se 


\section{REVISTAELETRONNICA \\ GRADUAÇ, ÁO/PÓS-GRADUAÇÃO EM EDUCAÇÃO \\ UFG/REJ}

ISSN. 1807-9342

Volume 14, número 1, ano 2018.

dá a reprodução de valores éticos por meio das práticas docentes e, para isso, fizemos uma breve apresentação da noção de ética.

Enquanto atores dentro das culturas, professores estão ao mesmo tempo em que se formam, na perspectiva da formação como um processo que ocorre antes, durante e depois da formação inicial (licenciatura), constituindo-se como agentes de legitimação (ou não) de determinadas práticas. Os professores se caracterizam como legítimos representantes de uma cultura e interlocutores com os quais seus alunos querem dialogar. Nesta dialogia instaura-se o processo descrito por nós de internalização em práticas culturais; ao conviver com seus professores, alunos vão sendo internalizados por modos de ser professor.

Para nós, então, tão importante quanto a discussão de quais conteúdos devem ou não estar na formação de professores, é a discussão de qual "modelo" de professor está, ou deveria estar, presente nesta formação. Neste ponto as noções de estranhamento e descentramento são uma perspectiva para a formação de professores que pode contribuir para a explicitação e discussão destas práticas sociais.

\section{REFERÊNCIAS}

ABBAGNANO, N. Dicionário de filosofia. trad. Alfredo Bossi; Ivone Castilho Benedetti. 5. ed. São Paulo: Martins Fontes, 2007.

ANGELO, C. L. Uma leitura das falas de alunos do ensino fundamental sobre a aula de Matemática. 2012. 160 f. Tese (Doutorado em Educação Matemática) - Universidade Estadual Paulista, Rio Claro, 2012.

BOGDAN, R.; BIKLEN, S. Investigação qualitativa em educação: Uma introdução à teoria e aos métodos. Porto: Porto Editora, 1994.

CARROLL, L. Alice no país das maravilhas. trad. Clélia Regina Ramos. São Paulo: Universo dos Livros, 2009.

COMPARATO, F. K. Ética: direito, moral e religião no mundo moderno. São Paulo: Companhia das Letras, 2006.

DANTAS, S. C.; FERREIRA, G. F.; PAULO, J. P. A. Uma noção de interação colaborativa elaborada à luz do Modelo dos Campos Semânticos e da Teoria da Atividade. Revista Paranaense de Educação Matemática. v. 5, n. 8, p. 213-236, jan.-jun., 2016.

FLICK, U. Qualidade na pesquisa qualitativa. Porto Alegre: Artmed, 2009. 


\section{REVISTA ELETRONNICA \\ GRADUAÇ, ÁO/PÓS-GRADUAÇÃO EM EDUCAÇÃO \\ UFG/REJ}

ISSN. 1807-9342)

Volume 14, número 1, ano 2018.

GARNICA, A. V. M. História Oral e Educação Matemática. 4. ed. In: BORBA, M. C.;

ARAÚJO, J. L. (Orgs). Pesquisa Qualitativa em Educação Matemática. Belo Horizonte:

Autêntica Editora, 2012.

HEGEL, G. W. F. Princípios da filosofia do direito. trad. Orlando Vitorino. São Paulo: Martins Fontes, 1997.

LINS, R. C. Luchar por la supervivencia: la producción de significado. Uno: revista de didáctica de las Matemáticas. n. 14, p. 39-46, out, 1997.

LINS, R. C. A formação exige prática. Nova escola. ano XVIII, n. 165, p. 14, set, 2003.

LINS, R. C. Matemática, monstros, significados e educação matemática. In: BICUDO, M. A. V. \& BORBA, M. C. (Orgs.). Educação Matemática: pesquisa em movimento. São Paulo: Cortez, 2004. p. $92-120$.

LINS, R. C. Escola também é cultura. Oficina de Educação. p. 6-7, set, 2010.

LINS, R. C. O Modelo dos Campos Semânticos: estabelecimentos e notas de teorizações. In. ANGELO, C. L. et al. Modelo dos Campos Semânticos e Educação Matemática: 20 anos de história. São Paulo: Midiograf, 2012. p. 11-30.

OLIVEIRA, V. C. A. Uma leitura sobre formação continuada de professores de matemática fundamentada em uma categoria da vida cotidiana. 2011. 207 p. Tese (Doutorado em Educação Matemática) - Universidade Estadual Paulista, Rio Claro, 2011.

PAULO, J. P. A. Contando uma história: ficcionando uma dissertação sobre a relação entre professor e aluno. 2016, 134 p. Dissertação (Mestrado em Educação Matemática) Universidade Estadual Paulista, Rio Claro, 2016a.

PAULO, J. P. A. Formação de professores como um processo de constituição de direções de interlocução. In: Escola de Inverno de Educação Matemática, 5., 2016, Santa Maria. Anais. Santa Maria: Universidade Federal de Santa Maria, 2016b. Não paginado.

VIOLA DOS SANTOS, J. R. Legitimidades possíveis para a formação matemática de professores de matemática (Ou: Assim falaram Zaratustras: uma tese para todos e para ninguém). 2012, 360p. Tese (Doutorado em Educação Matemática) - Universidade Estadual Paulista, Rio Claro, 2012. 